\title{
Research for profit
}

\author{
Technology development research worthy of publication takes place at many for-profit companies. At Nature \\ Methods, we do not treat such papers any differently than papers submitted from academic labs.
}

F or-profit companies both large and small provide reagents, kits, lab equipment, instruments, and computer hardware and software that are essential to lab-based research. Many company products have origins in academic labs: technology developments at universities may be licensed and commercialized by a company, or academic researchers may found spinoff companies, often funded by venture capital firms or angel investors. And many transformative tools, devices and instruments have resulted from research done entirely in-house at companies.

Industry research and product development benefits science in many ways. With ample resource availability at many companies, and a focus on efficiency and creation of viable products, technology development often proceeds much quicker in industry than in academic labs. Complex devices and instruments that require considerable time, money and expertise to build, can be made broadly available to the research community through commercialization - just try to imagine modern biology research without commercial sequencers, mass spectrometers or microscopes. The availability of off-the-shelf reagents and kits allows researchers to do routine work more time-efficiently and cost-effectively, avoiding the need for chemical synthesis or lengthly protocol optimization.

Savvy companies work closely with academic labs to listen to their wants and needs, and enlist their help in testing prototype products. Smart companies also send representatives to meetings and conferences to learn how they can support community demands, such as by facilitating conversion of proprietary instrument data formats to standard formats that can be shared.

Here at Nature Methods, we recognize that much research being done at or in collaboration with industry is of high scientific value, and we welcome such submissions; we also welcome and use researchers employed at companies as peer reviewers. Submissions from industry researchers are treated just the same as submissions from academic researchers; of highest interest to us is whether a method or tool is novel and whether its development

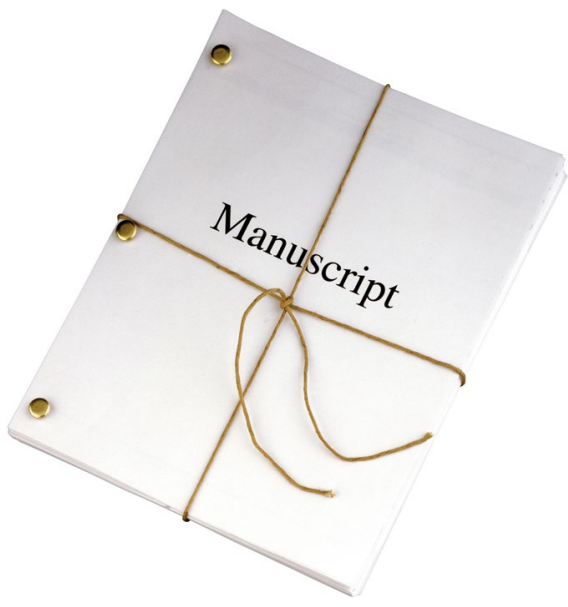

Credit: Getty

addresses a significant technical challenge in biological research. How that work is funded and any plans for commercialization (even if vague) should be disclosed to editors, reviewers and readers, but ultimately if the scientific development is exciting, novel and appropriately benchmarked, it does not matter where the work originates.

Transparency and reproducibility, however, are paramount to the methods papers that we publish; we make no exceptions to this rule for industry authors. Details about reagent identity, protocol steps, instrument design specs and software code must be disclosed, so that results can be reproduced by others, and data cannot be kept proprietary. Understandably, disclosing such information may compromise a company's business. Industry authors must assess whether the benefits of making their research known to the broader scientific community through publication outweigh the potential risks.

It is also always essential for authors from companies - and any academic authors who have an affiliation with or receive funding, equipment or supplies from a company, who hold stocks or shares in a company that may benefit from publication, or who file a patent application based on their work - to declare competing interests. Even when a company has no immediate plans to develop a product based on their research, the company still may indirectly benefit through publication in a well-regarded journal in terms of growing their reputation. Academic researchers must also declare their conflicts, even if there are no potential immediate or direct financial gains. There should be no shame in declaring competing interests, and the failure to do so is much more likely to damage reputations in the long run. See our full policy on competing interests here, https://go.nature.com/2Y42aEJ.

While labs and companies of course have a right to protect their own intellectual property through patents, such roadblocks can also stifle innovation or further expansion of technologies and thus hinder scientific progress. Our competing interest policy, however, only requires that authors declare any patent application plans; we do not dictate how this should proceed.

Even when companies choose not to fully disclose the details of how their technologies work through journal publication, we encourage them to provide adequate information through their websites and company materials, such that customers can determine for themselves whether product performance can be trusted.

Lastly, we want to point out that there is a major distinction between a scientific paper and an advertisement for a product. Companies who wish to promote specific products can do so through paid ads, advertorials and advertising features. Nature Methods editors are not involved in soliciting these; advertorials (such as Application Notes) are not peer reviewed and we take no responsibility for the accuracy of their content. Such paid advertisements should never be mistaken for or referred to as scientific publications.

There has long been a bias from many in the academic world that research done at non-profit institutions is better, more important and more altruistic than research done at for-profit companies, who many people assume care only about the bottom line. But industrial researchers are as much a part of the scientific ecosystem as academic researchers, funders and yes, even journal editors.

Published online: 30 July 2019

https://doi.org/10.1038/s41592-019-0514-8 